\title{
Alkali-assisted coal extraction with polar aprotic solvents
}

\author{
M.H. Makgato, L.J. Moitsheki, L. Shoko, B.L. Kgobane, D.L. Morgan, W.W. Focke* \\ SARChI Chair in Carbon Technology and Materials, Institute of Applied Materials, University of Pretoria, Pretoria 0002, South Africa
}

\section{A R T I C L E I N F O}

\section{Article history:}

Received 28 June 2008

Received in revised form 14 October 2008

Accepted 22 December 2008

Available online $\mathrm{xxxx}$

\section{Keywords:}

Coal

Solvent extraction

Coke

Graphite

\begin{abstract}
A B S T R A C T
Coal extraction experiments were conducted using a coal, containing ca. 10\% ash, from the Tshikondeni mine in South Africa. This coal dissolves only to a limited extent in pure polar aprotic solvents such as dimethylformamide (DMF) and N-methyl-2-pyrrolidinone (NMP). However, the addition of a strong base, e.g. sodium hydroxide $(\mathrm{NaOH})$ or sodium tert-butoxide increased the degree of coal dissolution in these organic solvents. Depending on the extraction conditions, carbon extraction efficiencies of up to $90 \%$ were obtained. Carbon precursor material was recovered from the solution as a gel by precipitation with water. Ash content was reduced from $10 \%$ in the coal to less than $1.6 \%$ in the coal extracts. Sodium sulfide $\left(\mathrm{Na}_{2} \mathrm{~S}\right)$ addition further reduced ash content and aided the recovery of carbon precursors that led to graphitizable cokes but the degree of extraction was significantly reduced.
\end{abstract}

(C) 2008 Elsevier B.V. All rights reserved.

\section{Introduction}

The presence of high levels of inorganic impurities has limited the use of coals as a source of cokes for synthetic graphite. While it is possible to chemically leach the bulk of such contaminants from coals, the reagents are expensive, difficult to recover and the process generates undesirable effluents [1,2]. Furthermore, the coal matrix tends to shield the mineral grains from the reagent and this limits the degree of purification that can be achieved [3]. Another option for the removal of the inorganic mineral components is to extract the organic part of the coal with solvents. However, coals show only limited solubility in neat solvents such as pyridine [4]. Hot NMP is an excellent extractant for suitable coals [5]. Coal extracts prepared by this method have been coked and graphitized [6]. However, high degrees of graphitization were only observed when the coal had been, to some degree, hydrogenated prior to having been extracted.

The Hyper-coal coal extraction process employs coal-derived aromatic solvents such as methyl-naphthalenes to de-ash coal [7]. These solvents have a high affinity for coal and feature excellent thermal stability. Coal extraction degrees approaching 70 wt.\% d.a.f. (dry and ash-free coal) were achieved with various ranks of coals at $350{ }^{\circ} \mathrm{C}$.

Solvent mixtures, e.g. blends of carbon disulphide and N-methyl-2pyrrolidinone (NMP), have also proven useful $[8,9]$. They are particularly effective dissolving up to $65 \%$ of the organic part of some coals at room temperature [9] and up to $85 \%$ at elevated temperatures [10-12].

The Refcoal process invented by Morgan [13] teaches the addition of sodium or potassium hydroxide to polar, aprotic solvents to enhance the solubilization of suitable coals [14]. The extraction proceeds smoothly at room temperature, with up to $90 \%$ of the organic

\footnotetext{
* Corresponding author. Tel.: +27 1283326 6549; fax: +27 124202516 .

E-mail address: walter.focke@up.ac.za (W.W. Focke).
}

part of high-rank bituminous coals being dissolved. The purpose of this communication is to review salient technical aspects of the Refcoal process. It reports on the extraction efficiency of various solvents and considers the effect of sodium sulfide as an extraction and coking additive.

\section{Experimental}

\subsection{Coal and reagents}

The coal used was a flotation product from the Tshikondeni mine, Limpopo Province, South Africa. These fines had a particle size below $150 \mu \mathrm{m}$. Analyses of coal (air-dry basis) were performed by Coal and Mineral Technologies (Pty) Ltd. The coal analysis is given in Table 1. The main chemicals used were: N,N-dimethylformamide (DMF) 99.9\% AR (Samsung Fine Chemicals); $\mathrm{NaOH} \mathrm{CP}$ in pearl form (Bio-Zone Chemicals), and hydrated $\mathrm{Na}_{2} \mathrm{~S}$ (60-62\%) (PAC Chemicals). Unless otherwise stated, all reagent ratios are expressed in mass terms.

\subsection{XRF analysis}

Elemental composition was determined by XRF analysis. A coal sample was ashed by roasting at $1000{ }^{\circ} \mathrm{C}$. Then $1 \mathrm{~g}$ of the residue was added to $9 \mathrm{~g} \mathrm{Li}_{2} \mathrm{~B}_{4} \mathrm{O}_{7}$ and fused into a glassed bead. Major element analysis was executed on the fused bead using an ARL9400XP+ spectrometer. The results are expressed in terms of the corresponding oxides.

\subsection{Extractions}

All operations were done under a nitrogen atmosphere. This is particularly important during the extraction, as traces of oxygen were 
Table 1

Proximate (air-dry-basis) and ultimate analysis of Tshikondeni coal

\begin{tabular}{lclr}
\hline Proximate analysis, \% & & Ultimate analysis (d.a.f), \% \\
\hline Moisture & 0.9 & Carbon & 90.86 \\
Ash & 9.4 & Hydrogen & 4.88 \\
Volatile matter & 23.3 & Nitrogen & 2.07 \\
Fixed carbon & 66.4 & Oxygen & 2.19 \\
Total sulphur & 0.81 & & \\
\hline
\end{tabular}

found to inhibit coal dissolution. Small-scale extractions were performed at room temperature in stainless-steel tubes $(80 \mathrm{ml}$ volume) fitted with screw caps and PTFE seals. Typically coal (7 g), solvent (70 g) and alkali were introduced together with a stainlesssteel slug ( $1 \mathrm{~cm}$ by $1 \mathrm{~cm}$ diameter). Air was displaced by nitrogen and the tubes sealed. Up to 12 tubes were placed in a tumbling apparatus and rotated end-over-end at $60 \mathrm{rpm}$ for $24 \mathrm{~h}$ at room temperature. The extract was filtered through No. 3 sintered-glass filter, washed once with solvent $(70 \mathrm{~g})$, then exhaustively with water to remove residual solvent and dried under vacuum at $60{ }^{\circ} \mathrm{C}$. The residue was weighed, the carbon content determined and the degree of coal extraction calculated.

In the bench-scale extractions, the extraction apparatus consisted of a jacketed stainless-steel reactor featuring internal baffles and fitted with a flat blade stirrer driven by a variable-speed motor capable of $1500 \mathrm{rpm}$. Oil or water from a thermostat was pumped through the jacket to provide temperature control. A stream of nitrogen was allowed to flow continuously into the reactor to maintain an inert environment. A typical extraction test was performed as follows: The reactor was loaded with solvent, (e.g. DMF $1000 \mathrm{~g})$ and coal (100 g) and heated to the operating temperature. The alkali (e.g. $\mathrm{NaOH}, 10 \mathrm{~g}$ ) was added and this point was taken as the starting time for extraction. Samples of the slurry were taken as required and the degree of extraction measured. Extractions were conducted over a period of about 5-6 h.

Experiments to determine the correlation between absorbance and the coal content of the solution was performed as follows. About $10 \mathrm{ml}$ samples were collected at certain time intervals and centrifuged for $5 \mathrm{~min}$ at $3000 \mathrm{rpm}$ for $5 \mathrm{~min}$ to remove inorganic mineral matter and undissolved coal. Then $4 \mathrm{~g}$ of supernatant was precipitated and washed with distilled water. The recovered coal extracts were dried under a flow of nitrogen and then weighed and analyzed for their carbon content. The degree of extraction was calculated as:

$\%$ coal extraction $y=100 \times\left[\frac{\text { mass carbon in coal-mass carbon in extract }}{\text { mass carbon in coal }}\right]$

For absorbance measurements, $0.1 \mathrm{~g}$ of the supernatant solution was weighed into a volumetric flask and diluted to $50 \mathrm{ml}$ with solvent. The absorbance of the solution was measured at a wavelength of $600 \mathrm{~nm}$ on a Spectronic Genesis-5 Ultraviolet spectrophotometer or a Unicam SP 1700 spectrophotometer using a cuvette with a path length of $10 \mathrm{~mm}$. Note that the absorbance was corrected to exactly $0.1 \mathrm{~g}$ of the sample per $50 \mathrm{ml}$ diluent. A calibration curve was obtained by plotting the absorbance of this diluted solution against the original coal content of the extract with the concentration expressed as wt.\%.

Coal dissolution kinetics was studied by following the change of absorbance with time. In these experiments, the extraction progress was monitored by sampling $\sim 2 \mathrm{ml}$ of the slurry at certain time intervals and treating as described above. The effects of temperature, nature of the alkali and the solvent, as well as addition of sodium sulfide, were considered in these experiments.

\subsection{Effect of other alkali and addition of sodium sulfide}

Similar experimental procedures were carried out using potassium hydroxide, sodium butoxide $\left(\mathrm{C}_{4} \mathrm{H}_{9} \mathrm{ONa}\right)$, sodium methoxide $\left(\mathrm{CH}_{3} \mathrm{ONa}\right)$
Table 2

Tshikondeni coal ash analysis

\begin{tabular}{llllllllllll}
\hline Component & $\mathrm{SiO}_{2}$ & $\mathrm{Al}_{2} \mathrm{O}_{3}$ & $\mathrm{Fe}_{2} \mathrm{O}_{3}$ & $\mathrm{P}_{2} \mathrm{O}_{5}$ & $\mathrm{TiO}_{2}$ & $\mathrm{CaO}$ & $\mathrm{MgO}$ & $\mathrm{K}_{2} \mathrm{O}$ & $\mathrm{Na}_{2} \mathrm{O}$ & $\mathrm{SO}_{3}$ & Total \\
\hline wt.\% & 51.4 & 25.5 & 6.00 & 0.82 & 2.24 & 5.05 & 2.52 & 1.46 & 0.36 & 4.45 & 99.79 \\
\hline
\end{tabular}

or lithium ethoxide $\left(\mathrm{C}_{2} \mathrm{H}_{5} \mathrm{OLi}\right)$ instead of $\mathrm{NaOH}$. In other experiments, keeping DMF to $\mathrm{NaOH}$ at constant at 10:1, the effect of sodium sulfide addition to the extraction medium was studied. The $\mathrm{NaOH}: \mathrm{Na}_{2} \mathrm{~S}$ molar ratios tested were $4: 1,2: 1$ and $1: 1$.

\subsection{Minerals and alkali removal}

Extracts were centrifuged at $6000 \mathrm{rpm}$ for $30 \mathrm{~min}$ and the supernatant filtered under vacuum through polypropylene filter cloth. The removal of minerals was monitored by XRF analysis of the recovered Refcoal.

\subsection{Refcoal recovery}

The dissolved coal was precipitated in polypropylene centrifuge bottles by adding a volume of water equal to that of the solution. The precipitate had a gel-like consistency. The gel was collected by centrifugation. It was re-suspended in the freshly distilled water having the same volume as that of the initial water added. The mixture was vigorously shaken for $3 \mathrm{~min}$ and then centrifuged at $4300 \mathrm{rpm}$ for $30 \mathrm{~min}$. This washing process was repeated three or four times. The recovered gel was dried in an oven, at $60{ }^{\circ} \mathrm{C}$ overnight.

\subsection{Refcoal coking and graphitization}

Dried Refcoal, obtained using DMF:coal:NaOH=100:10:1, was coked by heating to $480{ }^{\circ} \mathrm{C}$ at $10{ }^{\circ} \mathrm{C} / \mathrm{min}$, held at this temperature for $60 \mathrm{~min}$ and then heated, at $10{ }^{\circ} \mathrm{C} / \mathrm{min}$ to $900{ }^{\circ} \mathrm{C}$. Samples were coked in a Geisseler plastometer. Polished blocks were examined using reflectance microscopy. A sample of the coke prepared from the room-temperature, no sulphide-extract was graphitized at $2900{ }^{\circ} \mathrm{C}$, for $6 \mathrm{~h}$, in a plasma-heated furnace. Raman spectra and X-ray diffractograms were measured on the graphitized samples. The ratios of the areas of the Raman "graphite" and "disorder" peaks at about $1580 \mathrm{~cm}^{-1}$ and $1350 \mathrm{~cm}^{-1}$, respectively were calculated. The Maire and Mering graphitization factor, $g$, was calculated from the graphite interlayer distance, $d_{002}$, measured in $\mathrm{nm}[15]$ :

$g=\left(0.344-d_{002}\right) / 0.0086$

A similar extraction was done, with the addition of sodium sulphide. The reagent ratios were: DMF:Coal: $\mathrm{NaOH}: \mathrm{Na}_{2} \mathrm{~S}=100: 10: 1: 2.3$

Table 3

Major petrographic characteristics of Tshikondeni coal

\begin{tabular}{ll}
\hline Rank (degree of maturity) & $\begin{array}{l}\text { Meta-bituminous } \\
\text { (Medium rank B) }\end{array}$ \\
ACE-UN in-seam classification & 1.33 \\
Mean random reflectance (\%) & V10-V16 \\
Vitrinite-class distribution & 0.117 \\
Standard deviation ( $\sigma)$ & Extended vitrinite-class distribution \\
Abnormalities & \\
& \\
Petrographic composition - analysis of macerals & 93 \\
Vitrinite content (\%) & $<1$ \\
Liptinite content (\%) & 94 \\
Total reactive macerals (\%) & 6 \\
Total inertinite (\%) & 1 \\
More highly reflecting materials (\%) & Occasionally observed \\
Cracks and fissures & Very occasionally seen \\
Signs of advanced weathering or thermal effects & \\
\hline
\end{tabular}




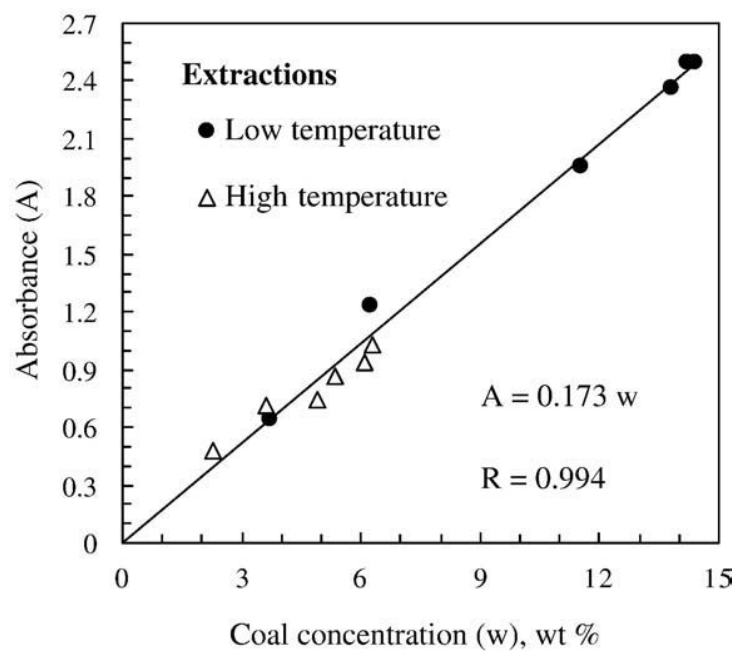

Fig. 1. Correlation between the absorbance and the coal content in wt.\% in DMF solutions obtained by room temperature and high temperature $\left(135^{\circ} \mathrm{C}\right)$ extractions.

( $\mathrm{NaOH}: \mathrm{Na}_{2} \mathrm{~S}$ : molar ratio of $1: 1$ ). This material was similarly recovered, coked, graphitized and characterized.

\section{Results and discussion}

Tables 1, 2 and 3 provide details on the coal petrography and proximate analysis. The oxygen content (\%) was obtained by difference. The coal used is classified as a meta-bituminous (medium rank B) and has a high vitrinite content of $93 \%$. Silicon is the main constituent element in the ash.

\subsection{Coal solution properties}

The Refcoal solutions are dark brown to black in color depending on the concentration. The viscosity of saturated DMF solutions ranged from $1.8 \mathrm{mPa}$ s at $90^{\circ} \mathrm{C}$ to $3.5 \mathrm{mPa}$ s at $30^{\circ} \mathrm{C}$. Solutions in both DMF and NMP are unstable when exposed to atmospheric water and carbon dioxide. The NMP solutions have an indefinite stability when in closed containers, but the DMF solutions gel after a few weeks. The addition of acid, water or other solvents miscible with DMF and NMP leads to immediate precipitation of the coal-derived material. Fig. 1 shows the relationship between the absorbance and the coal content of DMF solutions. The absorbance varies linearly with extract concentration in agreement with the Beer-Lambert law (correlation coefficient $R=0.994$ ). The value of the mass absorption coefficient was determined as $17.3 \pm 1.8 \mathrm{wt} . \%^{-1} \cdot \mathrm{m}^{-1}$ using least squares data regression.

\subsection{Effect of solvent}

A number of solvents were examined for extraction power. The conditions used were: solvent:coal: $\mathrm{KOH}=100: 10: 1.56$. Except for pyridine, which extracted $4 \%$, only traces of coal were dissolved $(<2 \%$ for all other solvents tested) when the alkali was left out. The following solvents remained ineffective, dissolving once again only trace amounts, even when alkali was added: Diethyleneglycol dimethylether, tetraethyleneglycol dimethylether, morpholine, piperidine, tetrahydrofuran, ethanol and formamide. Fig. 2 shows that highly polar aprotic solvents give good extraction together with alkali.

\subsection{Alkali content}

Fig. 3 shows the results of experiments aimed at optimizing the alkali content using DMF as solvent. The alkali was added as a 50\% solution in water. The reagent ratios were DMF:coal:KOH=100:10: $x$. An optimum quantity for both alkalis is indicated. It is interesting that the degree of extraction appears less sensitive to the quantity of sodium hydroxide, as compared with potassium hydroxide. These experiments require amplification, particularly in view of the interesting effects on the extraction shown by alkali, solvent and water content, as will be seen in the following section.

\subsection{Effect of water}

The probable importance of water prompted an examination of the effect of drying the solvents before extraction, and of adding varying quantities of water to the extraction experiments. The conditions were: solvent:coal:alkali=100:10:1.14. The results are given in Fig. 4. Drying the as-received solvents over molecular sieves lead to no significant change in the solvency power. The addition of water to NMP seems to have very little effect when using $\mathrm{KOH}$ as base, and not much more when using $\mathrm{NaOH}$. Dimethylformamide, however, is seriously affected when either base is used. This is tentatively attributed to the base catalyzed hydrolysis of DMF to dimethyl amine and formic acid in the presence of water.

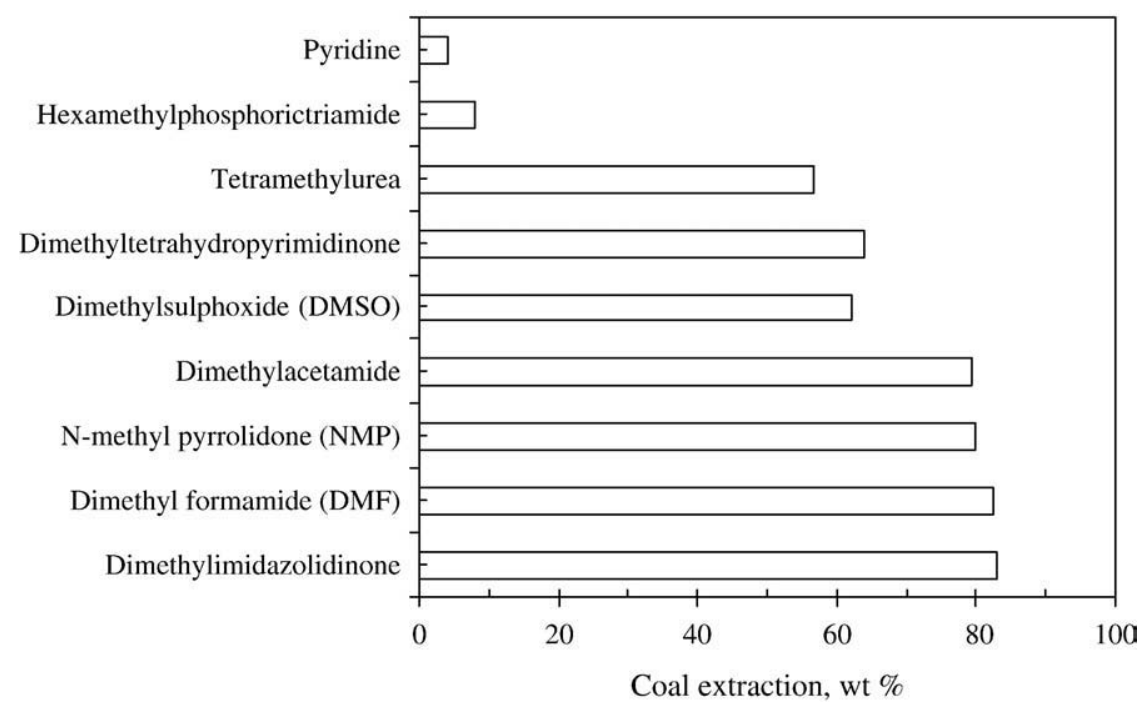

Fig. 2. The effect of solvent nature on the extraction efficiency at ambient conditions. Solvent: $\mathrm{coal}: \mathrm{KOH}=100: 10: 1.56$ on a mass basis. 


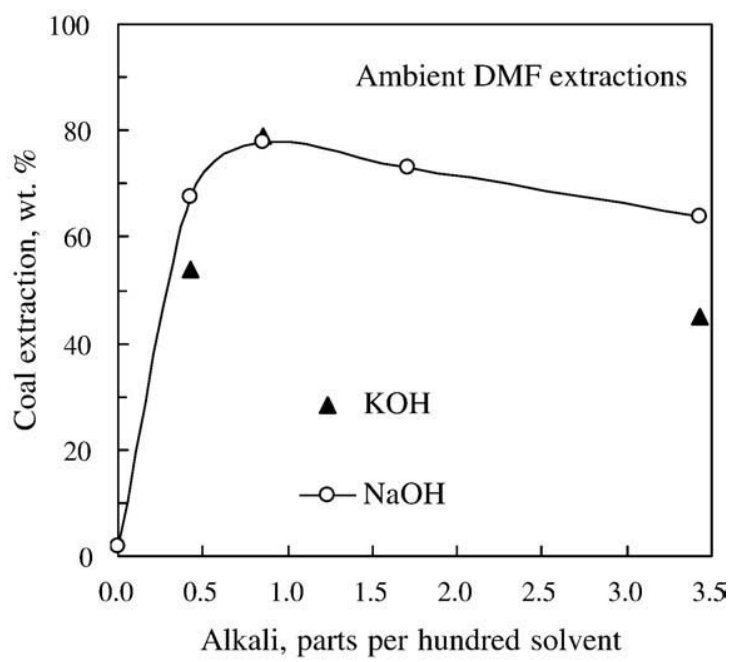

Fig. 3. The effect of alkali quantity on the extraction in DMF. Reagent ratios were: DMF: coal:base $=100: 10: x$ where $x$ is the amount of alkali per 100 parts solvent.

\subsection{Solvent to coal ratio}

A process employing the lowest possible solvent:coal ratio would be desirable. Extractions were performed using differing coal:solvent ratios, but keeping the coal: $\mathrm{NaOH}$ ratio the same at 10:1.56 with the alkali added as a 50\% aqueous solution. The results are given in Fig. 5. The degree of coal extraction did not change in the case of NMP as solvent. This implies that the solubility limit of coal in NMP was not surpassed and that it must exceed $40 \mathrm{~g} / 100 \mathrm{~g}$ NMP. The degree of extraction for DMF shows a linear decline with increasing coal to solvent ratio. This behavior is consistent with a solubility limit of $17.6 \pm$ $2.2 \mathrm{~g} \mathrm{coal} / 100 \mathrm{~g}$ DMF at ambient conditions.

\subsection{Dissolution kinetics: effect of base used and extraction temperature}

As mentioned, the coal dissolution kinetics was followed indirectly by measuring the change in absorbance of the liquid phase and calculating the coal content from the correlation shown in Fig. 1. An increase in the absorbance indicates that coal dissolves in the solvent. DMF, DMAA or NMP alone are poor solvents for dissolving coal. This is substantiated by the lack of change in the color intensity of the

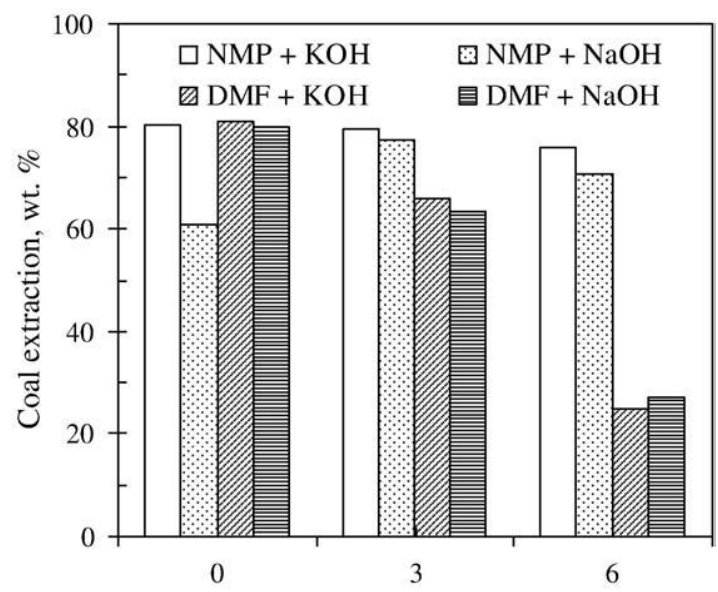

Water added, parts per hundred solvent

Fig. 4. The effect of varying quantities of water on the extraction efficiency. The conditions were: solvent:coal:alkali: $\mathrm{H}_{2} \mathrm{O}=100: 10: 1.14: x$ where $x$ is the water added per hundred parts solvent.

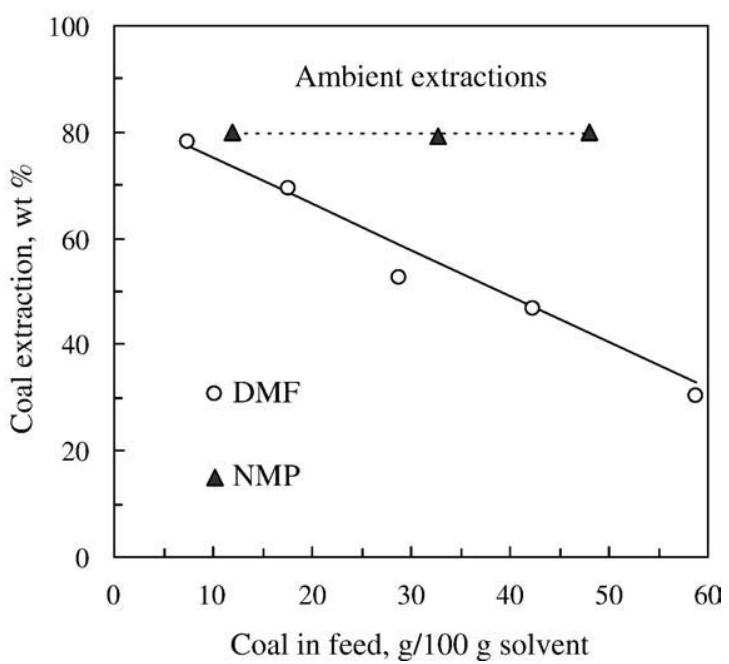

Fig. 5. The effect of the solvent:coal ratio on the degree of extraction. Reagent ratios were: solvent:coal:alkali $=100: x: 0.156 x$ where $x$ is the mass of coal per hundred parts solvent.

solution even after $5 \mathrm{~h}$ of extraction. Fig. 6 shows that coal solubility in polar aprotic solvents is increased by the addition of strong bases such as $\mathrm{NaOH}$. It also shows the progress of coal dissolution using DMF and various strong bases. The extraction curve for solid $\mathrm{NaOH}$ indicates a clear induction period before dissolution commences. $\mathrm{CH}_{3} \mathrm{NaO}$, $\mathrm{C}_{2} \mathrm{H}_{5} \mathrm{LiO}$ and $\mathrm{C}_{4} \mathrm{H}_{9} \mathrm{NaO}$ are more soluble in DMF than $\mathrm{NaOH}$. This makes these bases more readily available for dissolving coal in the organic solvent. The effect is a significant reduction in the induction period during extraction process. This is also true for extractions conducted at elevated temperatures. See Fig. 7.

\subsection{Effect of sodium sulphide on extraction, coking and graphitization}

During the extraction process using DMF and $\mathrm{NaOH}, \mathrm{Na}_{2} \mathrm{~S}$ was introduced into the extraction vessel. According to Iino and Matsuda, $\mathrm{Na}_{2} \mathrm{~S}$ releases $\mathrm{S}^{2-}$ ions into the medium thereby forming insoluble metal-sulfide complexes [8]. The intention was to precipitate any metal impurities to aid their removal with the ash residue separated from the Refcoal solution. The curve for $\mathrm{NaOH}: \mathrm{Na}_{2} \mathrm{~S}=4: 1$ (mole ratio) in Fig. 8 is similar in shape to that for the extraction without sodium sulfide. The only difference was that less coal was extracted. Addition of higher $\mathrm{Na}_{2} \mathrm{~S}$ levels had a surprising and unexpected effect on the extraction curves. An induction time was not discernable and clear

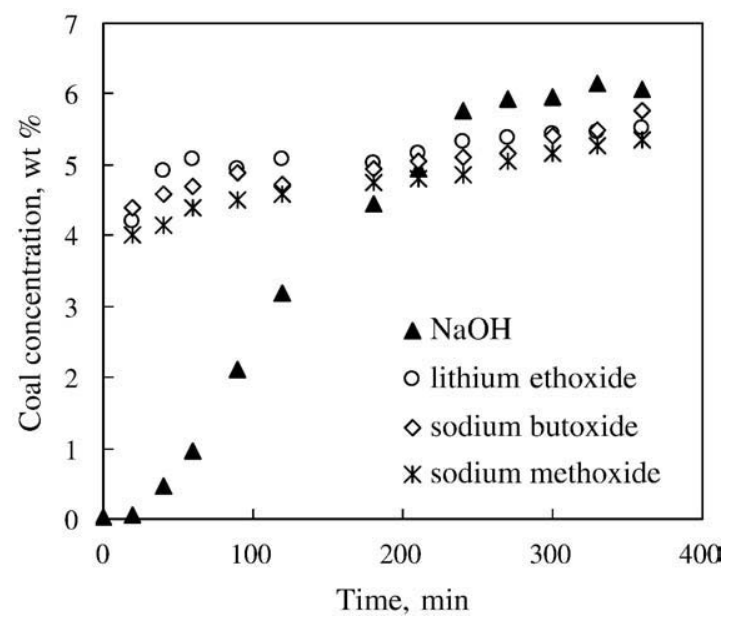

Fig. 6. The effect of different alkalis on the rate of coal dissolution at ambient conditions. Reagent ratios were: DMF:coal:alkali=100:10:1. 


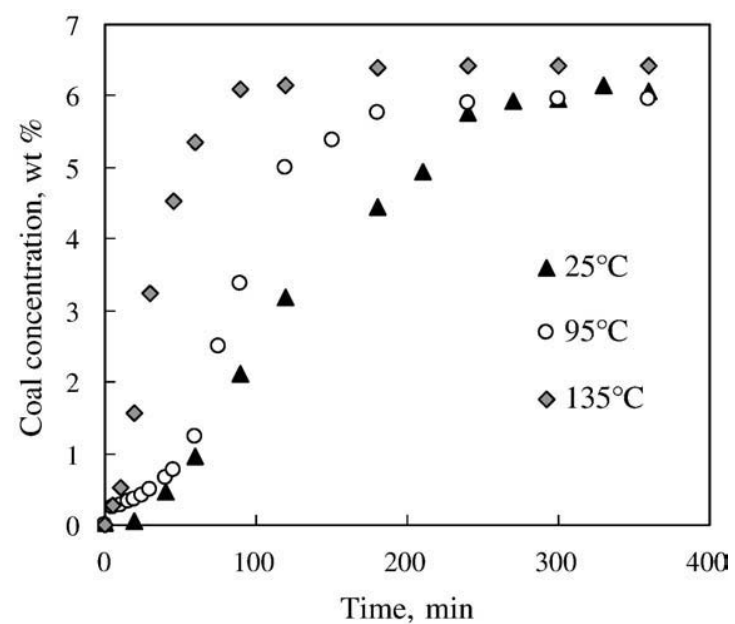

Fig. 7. The effect of temperature on the rate of coal dissolution. Reagent ratios were: DMF:coal: $\mathrm{NaOH}=100: 10: 1$.

maxima in the degree of extraction were observed. Nevertheless, a plateau value is reached at long extraction times. The implication is that the sulfide initially aids solubilization but that subsequently some precipitation occurs. High $\mathrm{Na}_{2} \mathrm{~S}$ dosage (1:1 $\mathrm{NaOH}: \mathrm{Na}_{2} \mathrm{~S}$ mole ratio) adversely affected the degree of extraction. The observed decrease in the color intensity correlated with a low yield of the coal extracts. See Table 4.

The elemental analysis of the dried Refcoal is given in Table 4. Without $\mathrm{Na}_{2} \mathrm{~S}$, the coal extracts showed an ash content of $1.6 \%$ (by weight). Increasing the sulfide dosage caused a gradual decrease in the ash content: The ash content values were 1.3, 1.0, and 0.7 (wt.\%) corresponding to $\mathrm{NaOH}: \mathrm{Na}_{2} \mathrm{~S}$ : molar ratios of $4: 1,2: 1$, and $1: 1$ respectively.

The following remarks refer to Refcoal samples obtained at different temperatures using reagent ratios of DMF:coal: $\mathrm{NaOH}=100: 10: 1$ or DMF:coal: $\mathrm{NaOH}: \mathrm{Na}_{2} \mathrm{~S}=100: 10: 1: 2.3$. Plastometry showed that maximum fluidity occurred for all samples between 465 and $475{ }^{\circ} \mathrm{C}$. The $\mathrm{Na}_{2} \mathrm{~S}$-free extract obtained at $90{ }^{\circ} \mathrm{C}$ was barely fluid, whilst the other extracts became fluid, in the following order: Ambient+ $\mathrm{Na}_{2} \mathrm{~S}>90^{\circ} \mathrm{C}+\mathrm{Na}_{2} \mathrm{~S}>$ ambient, no $\mathrm{Na}_{2} \mathrm{~S}$. The ranking of the coke swelling were exactly analogous, with the coke volumes, in the same order, being approximately 12,15 and 18 times that of the extract obtained at $90{ }^{\circ} \mathrm{C}$ in the absence of $\mathrm{Na}_{2} \mathrm{~S}$. The coke yields were approximately $75 \%$ for the samples without sulphide and $73 \%$ for those with sulphide.

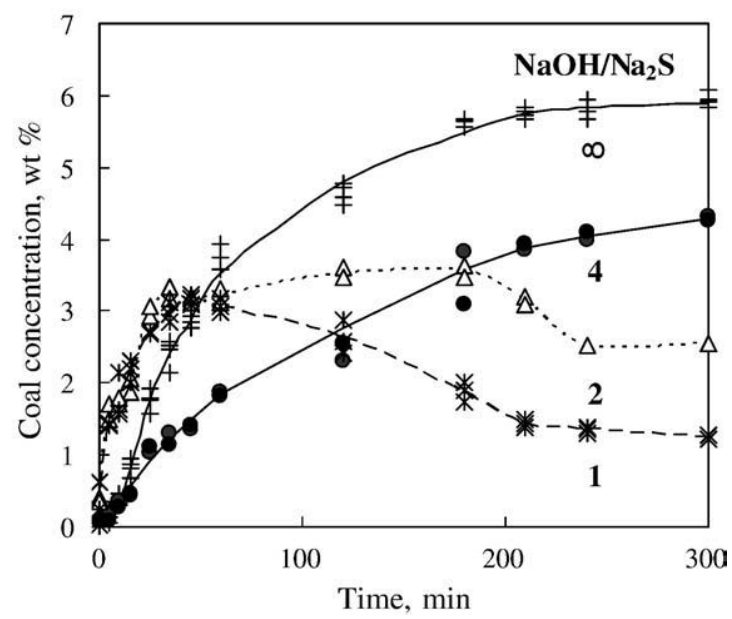

Fig. 8. The effect of sodium sulphide on the rate of coal dissolution at ambient conditions. The base reagent ratio was:DMF:coal: $\mathrm{NaOH}=100: 10: 1$ to which various amounts of sodium sulfide were added. Mol ratios $\mathrm{NaOH}: \mathrm{Na}_{2} \mathrm{~S}$ from 1 to 4 were evaluated.
Table 4

Effect of $\mathrm{Na}_{2} \mathrm{~S}$ addition on the degree of extraction and the elemental composition of the Refcoal coal extracts

\begin{tabular}{llllllll}
\hline $\begin{array}{l}\mathrm{NaOH}: \mathrm{Na}_{2} \mathrm{~S} \\
\text { molar ratio }\end{array}$ & $\begin{array}{l}\text { Extraction } \\
\text { degree (wt.\%) }\end{array}$ & \multicolumn{6}{l}{ Elemental analysis (wt.\%) } \\
\cline { 3 - 8 } & $\mathrm{C}$ & $\mathrm{H}$ & $\mathrm{N}$ & $\mathrm{O}$ & $\mathrm{S}$ & Ash \\
\hline$\infty$ & 82 & 85.2 & 4.43 & 2.06 & 7.49 & 0.86 & 1.60 \\
4 & 64 & 84.5 & 5.53 & 3.35 & 5.78 & 0.82 & 1.30 \\
2 & 49 & 85.2 & 5.45 & 2.80 & 5.72 & 0.85 & 1.00 \\
1 & 27.5 & 86.5 & 5.53 & 2.19 & 5.04 & 0.75 & 0.70 \\
\hline
\end{tabular}

Microscopic examination of polished samples, in polarized light, showed that the coke obtained from the $\mathrm{Na}_{2} \mathrm{~S}$-free extract obtained at $90{ }^{\circ} \mathrm{C}$, was essentially isotropic. The other three samples were highly anisotropic, showing large flow structures. The Raman and XRD results allowed the same conclusions to be drawn. The extract done at room temperature, with sulphide addition was most highly graphitized, followed by the $90{ }^{\circ} \mathrm{C}$ with sulphide extract and then the room temperature without sulphide extract. See Table 5 . Although the $90^{\circ} \mathrm{C}$, no $\mathrm{Na}_{2} \mathrm{~S}$ extract coke was not graphitized, it was clearly much less ordered than the other samples.

\section{Comments on the effect of solvent nature on extraction behavior}

A proper understanding of the organic structure of a coal could aid rationalization of its solvent extraction behavior. Unfortunately this is still unfinished business but a recent review paper [16] highlights the following: Coal has a macromolecular structure with a molar mass distribution falling in the 1300-3500 amu range. In addition it contains significant amounts of relatively low molecular mass substances ( 100-500 amu range). Presumably all known intermolecular forces hold the coal organic matter together but only the presence of hydrogen bonds has been directly detected.

The solvation power of a solvent is determined by all the operative intermolecular solute-solvent interactions. These microscopic intermolecular forces include dispersive interactions, hydrogen bonding and electron-pair-donor electron-pair-acceptor interactions. In practice, solvent polarity is measured empirically by means of convenient solvent-sensitive reference processes [17]. Almost two hundred such quantitative measures of solvent polarity have been proposed [18]. Some of the more important parameters include Kosower's $Z[19,20]$, Reichardt and Dimroth's $E_{\mathrm{T}}(30)$ [21], Gutmann's donor (DN) [22] and acceptor numbers (AN) [23], the hydrogen bond donation and acceptance abilities ( $\alpha$ and $\beta$ respectively) [20,24], the polarizability parameter $\pi^{*}[20,24]$, and Swain et al.'s $A$ (Acity) and $B$ (Basity) parameters [25].

The effect of solvent polarity on a given process or property cannot be uniquely assessed by using any single physical constant $[18,24]$. Kamlet et al. [24] suggest that five are relevant for linear solvation energy relationships. Marcus [20] indicates that at most four independent parameters may be required to describe solvent effects. These are: (i) a parameter characterizing the Lewis acidity or hydrogen bond donation ability. Marcus [20] states that any one of AN, $\alpha, E_{\mathrm{T}}(30)$, $Z$ or Acity can be used for this purpose. (ii) A parameter characterizing the electron pair donation, Lewis basicity or hydrogen bond acceptance ability. This is best accounted for by the descriptors DN or $\beta$. (iii) A parameter that measures the ability of the solvent to stabilize a neighboring charge or dipole [21], best characterized by $\pi^{*}$,

Table 5

Variation of ratios of the area of Raman graphite and disorder peaks, the interlayer spacing, $d_{002}$, and calculated Maire and Mering [15] graphitization factor, $g$

\begin{tabular}{llll}
\hline Extraction conditions & Raman $g / d$ & $d_{002}(\mathrm{~nm})$ & $g$ \\
\hline Ambient, no $\mathrm{Na}_{2} \mathrm{~S}$ & 1.75 & 0.33853 & 0.64 \\
$90{ }^{\circ} \mathrm{C}+\mathrm{Na}_{2} \mathrm{~S}$ & 6.7 & 0.33763 & 0.74 \\
Ambient $+\mathrm{Na}_{2} \mathrm{~S}$ & 7.0 & 0.33723 & 0.79 \\
\hline
\end{tabular}


and (iv) the solvent stiffness as measured by Hildebrandt's cohesive energy density parameter, $\delta^{2}$. Reichardt [21] and Swain et al. [25] indicate that most solvent effects can be rationalized in terms of only two complementary solvent property scales.

The extent of swelling of a coal appears to correlate well with the solvent electron-donor number [16,26,27]. Marzec and Kisielow [28] described the solvent extraction and swelling behavior of coal in terms

A

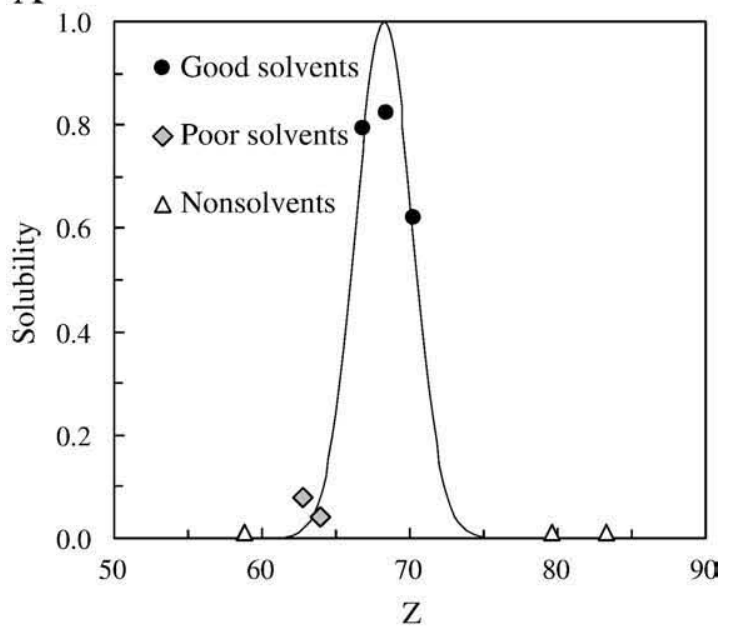

B

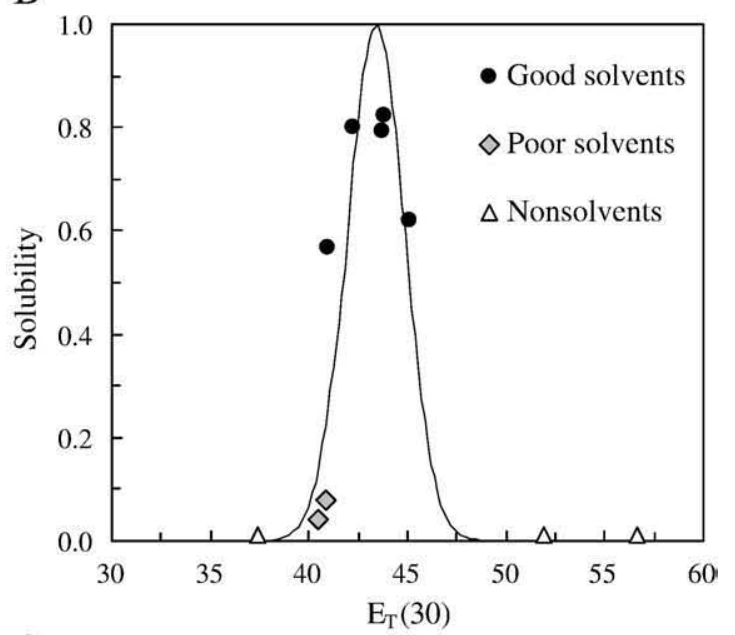

C

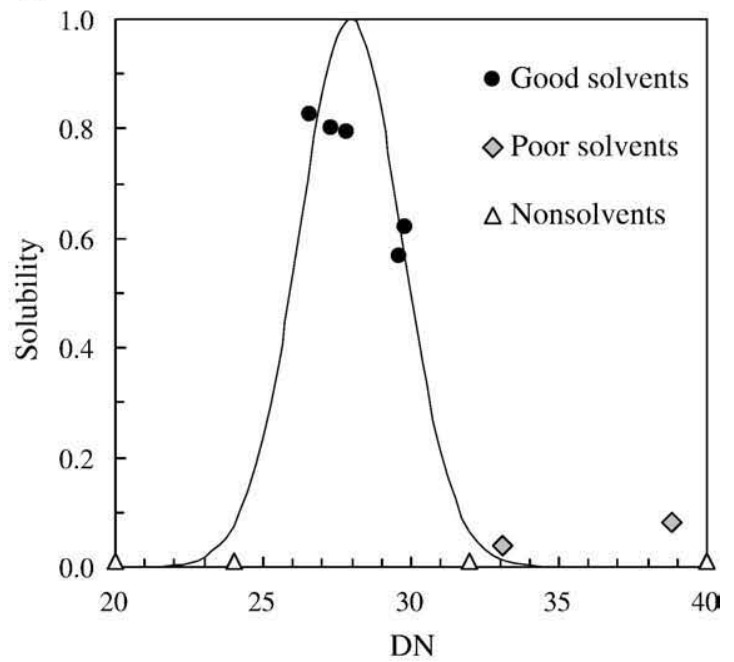

Fig. 9. Experimental extraction data plotted against the polarity indices $(A) Z$, (B) $E_{\mathrm{T}}(30)$, and (C) DN. Solid lines show fits of Eq. (3).
Table 6

Correlation coefficients and least squares regression parameters obtained by fitting Eqs. (3) and (4) to extraction data

\begin{tabular}{lllllll}
\hline Polarity parameter(s) & \# solvents & $R^{\mathrm{a}}$ & $\mu_{1}$ & $\sigma_{1}$ & $\mu_{2}$ & $\sigma_{2}$ \\
\hline$E_{\mathrm{T}}(30)$ & 12 & 0.913 & 43.4 & 1.0 & & \\
$\mathrm{DN}$ & 11 & 0.979 & 28.0 & 1.2 & & \\
$Z$ & 8 & 0.988 & 68.3 & 1.4 & & \\
$\mathrm{DN}+E_{\mathrm{T}}(30)$ & 11 & 0.987 & 28.5 & 1.5 & 43.2 & 1.0 \\
$\mathrm{DN}+Z$ & 8 & 0.998 & 28.4 & 1.5 & 68.3 & 1.1 \\
\hline
\end{tabular}

a Correlation coefficient.

of both electron-donor and electron-acceptor properties. Jones and Argasinski [29] also considered these factors as predictors of solvent effectiveness for the dissolution of coal pre-asphaltenes.

Hall et al. [30] suggested that the mechanism of swelling of the macromolecular structure of coals in basic solvents is one of breakage of hydrogen bonds. They found that swelling properties correlated better with $\mathrm{pK}_{\mathrm{b}}$ values than electron donor number values. Dyrkacz and Bloomquist [31] also concluded, on the basis of extraction results obtained with solvent blends, that the "basicity of the solvent is a major contributor to the extraction of coal". Giray et al. [32] studied the extraction of Argonne Premium coals using a 1:1 (by volume) mixture of $\mathrm{CS}_{2}$-NMP. They found that small additions of aromatic amines significantly improved extraction yields. They argue that hydrogen bonding between the amines and coal, rather than electron donoracceptor interactions, are responsible for this effect. Otake and Suuberg [33] studied the solvent swelling kinetics of a suite of low rank US coals. The observed activation energies were consistent with the hypothesis that the activation barrier is associated with the breakage of internal electron donor-acceptor (e.g. hydrogen bonding) interactions.

It should be noted that parameters such as the donor number (DN) are relevant to describe electron pair donation of which hydrogen bond acceptance ability is a special case. Thus it can safely be said that most authors concur that the solvent extraction ability is significantly dependent on the electron-donor properties of the solvent [16,26,27]. In this context the mechanism of coal extraction involves a substitution wherein the electron-donating solvent molecules replace the coal electron-donor participants $[16,26]$.

In the present study, the coal extraction data is further complicated by fact that a strong base was added together with the solvent. Clearly this could lead to salt formation, e.g. by reaction with phenolic or carboxylic acid functional groups. It is possible that the resulting charged species may enhance solvation by processes such as micellar solubilization. Nevertheless, we investigated whether a single parameter or pairs of polarity parameters $\left(x_{1}, x_{2}\right) \in\left\{\mathrm{A}, \mathrm{B}, \mathrm{AN}, \mathrm{DN}, \mathrm{Z}, E_{\mathrm{T}}(30)\right.$, $\left.\alpha, \beta, \pi^{*}\right\}$ were able to fit the current solubility data. The solubility was characterized by the fractional coal extraction values $(y)$ measured at ambient conditions for each solvent. Values of the solvent polarity descriptors were taken from Marcus [20]. The analysis was limited to the twelve solvents for which descriptors values were available. These solvent were classified in subsets as follows: non-solvents \{morpholine, piperidine, tetrahydrofuran, ethanol, formamide\}, poor solvents with fractional extraction $<0.1$ pyridine, hexamethylphosphoramide\} and good solvents with fractional extraction $>0.5$ tetramethylurea, dimethylsulphoxide, dimethylacetamide, dimethylformamide, N-methyl pyrrolidone\}. In most cases no correlation between solubility and polarity variable could be discerned when plotting the solubility data against individual polarity parameters. Where a functional correspondence was evident, it occurred in narrow range of parameter values as shown in Fig. 9. Therefore Gaussian-type functional forms were used to fit the extraction data:

Single parameter:

$y\left(x_{1}\right)=\exp \left[-\frac{1}{2}\left(\frac{x_{1}-\mu_{1}}{\sigma_{1}}\right)^{2}\right]$ 
Two parameters:

$y\left(x_{1}, x_{2}\right)=\exp \left[-\frac{1}{4}\left\{\left(\frac{x_{1}-\mu_{1}}{\sigma_{1}}\right)^{2}+\left(\frac{x_{2}-\mu_{2}}{\sigma_{2}}\right)^{2}\right\}\right]$

Where $y$ is the fractional extraction, $x_{i}$ represents polarity parameter $i$ and $\mu_{i}$ and $\sigma_{i}$ are adjustable constants. The constant $\mu_{i}$ indicates the parameter value for maximum extraction and the constant $\sigma_{i}$ provides a measure of the spread in the polarity parameter values where good solubility is observed.

The extraction data were fitted using least squares data regression and the goodness of fit assessed using the correlation coefficient between predicted and experimental extraction values. It was found that the degree of extraction was an unambiguous function of only three of the parameters namely $A N, Z$ and $E_{\mathrm{T}}(30)$. See Fig. 9. The best fit was obtained using Kosower's $Z$ parameter. The correlation results are shown in Table 6.

With two-parameter correlations it is important that the variables be orthogonal, i.e. they should not be correlated. For the current set of solvents, $Z$ and $E_{\mathrm{T}}(30)$ are, as expected, strongly correlated $(R=0.993)$. Furthermore, $Z$ shows virtually no correlation with the donor number DN $(R=-0.071)$ while the corresponding value for $E_{\mathrm{T}}(30)$ is also low and equal to $R=-0.306$. Fig. 10 shows the predicted regions for good solvent parameter values, i.e. where extraction values exceeding $50 \%$,
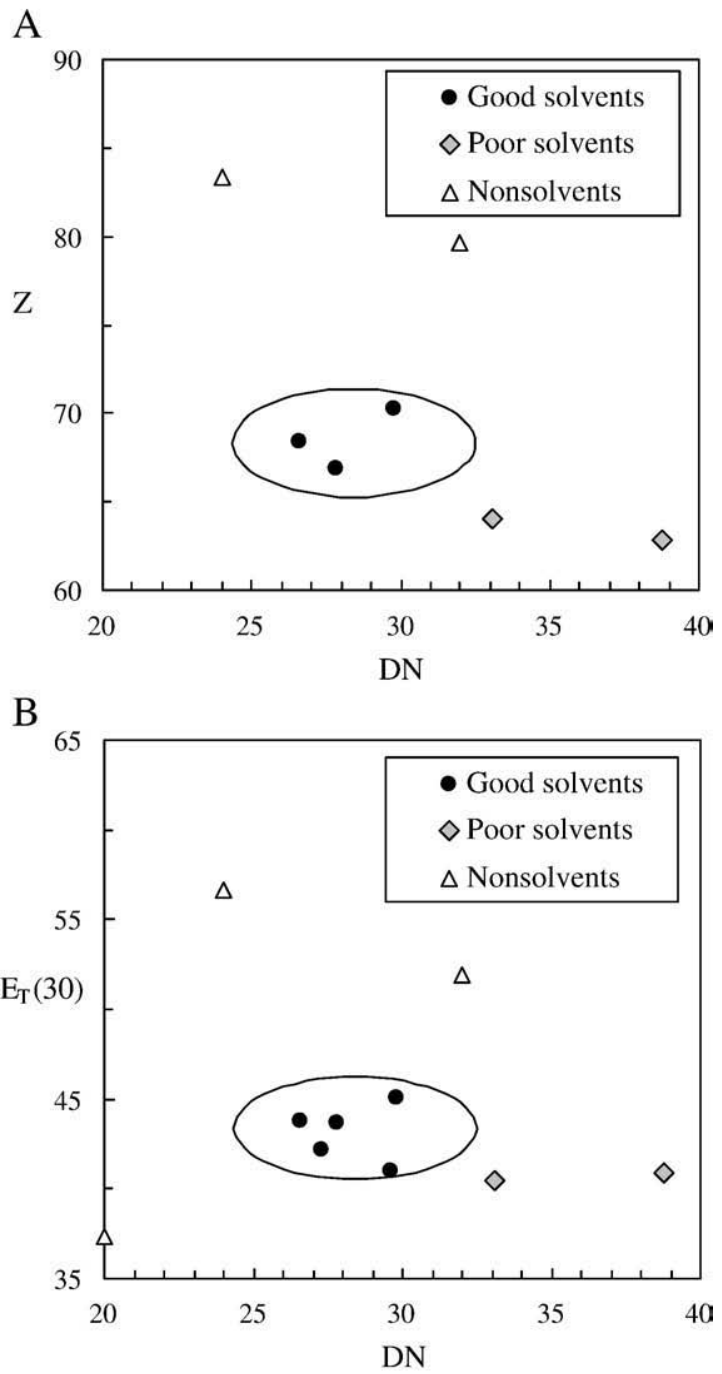

Fig. 10. Two dimensional scatter plots showing predicted regions of good solvent (fractional extraction $>50 \%$ ) parameter values for $(\mathrm{A}) Z$ and $\mathrm{DN}$, and (B) $E_{\mathrm{T}}(30)$ and $\mathrm{DN}$. are expected. In the present case the basicity of the solvent is not a major factor. This makes sense in view of the fact that a stronger base was purposefully added and that it could have caused breakage of hydrogen bonds via salt formation. However, it is interesting that even in the present case, the electron pair donor ability parameter (DN) effectively describes (i.e. "explains") the extraction efficiencies of the good solvents. However, many more solvents need to be tested before definitive, i.e. statistically significant, conclusions can be drawn.

\section{Conclusions}

The solubilization of a flotation product coking coal from the Tshikondeni mine was investigated. This bituminous coal showed very limited solubility in neat solvents except pyridine (solubilization $<4 \%$ ). However, addition of a strong alkali to polar, aprotic solvents such as DMF or NMP enhanced their extraction power significantly. Solubilization proceeded smoothly at ambient conditions and the degree of extraction approached $90 \%$ of the available carbon. The optimum quantity of sodium hydroxide required for maximum extraction in both solvents is about $10 \%$ of the mass of the coal. The solubility of the coal in NMP at ambient conditions exceeds $40 \mathrm{~g} / 100 \mathrm{~g}$ solvent. In DMF the corresponding solubility is about $18 \mathrm{~g} / 100 \mathrm{~g}$ solvent. The extraction efficiency is severely affected by the presence of air, with approximately half the potential extraction being obtained. The extraction rate increases rapidly with temperature. In DMF the time to completion ranges from slightly more than $1 \mathrm{~h}$ at $135^{\circ} \mathrm{C}$ to several hours at $25^{\circ} \mathrm{C}$. An induction period is seen at lower temperatures, especially when the base is added in solid form. $\mathrm{Na}_{2} \mathrm{~S}$ addition provides for higher purity coal extracts favorable for producing graphitizable carbon. The improved graphitizability comes at the cost of additional reagent and reduced coal recovery.

\section{Acknowledgements}

Financial support for this research from the THRIP program of the Department of Trade and Industry and the National Research Foundation of South Africa as well as PBMR and CSIR is gratefully acknowledged.

\section{References}

[1] K.M. Steel, J. Besida, T.A. O, Donnell, D.G. Wood, Production of ultra clean coal, Part I. Dissolution behaviour of mineral matter in black coal toward hydrochloric and hydrofluoric acids, Fuel Process. Technol. 70 (2001) 171-192.

[2] S. Mukherjee, P.C. Borthakur, Chemical demineralization, Fuel 80 (2001) 2037-2040.

[3] K.M. Steel, J. Besida, T.A. O, Donnell, D.G. Wood, Production of ultra clean coal, Part III. Effect of coal's carbonaceous matrix on the dissolution of mineral matter using hydrofluoric acid, Fuel Process. Technol. 76 (2002) 51-59.

[4] J.R. Pullen, Solvent extraction of coal, in: M.C. Gorbaty, J.W. Larsen, I. Wender (Eds.), Coal Science, vol. 2, Academic Press, 1983, p. 173.

[5] K. Ranganathan, J.W. Zondlo, E.A. Mintz, P. Kneisl, A.H. Stiller, Preparation of an ultralow ash coal extract under mild conditions, Fuel Process. Technol. 18 (1988) 273-278.

[6] M.S. Seehra, A.S. Pavlovic, V.S. Babu, Measurements and control of anisotropy in ten coal-based graphites, Carbon 32 (1994) 431-435.

[7] N. Okuyama, N. Komatsu, T. Shigehisa, T. Kaneko, T. Tsuruya, Hyper-coal process to produce the ash-free coal, Fuel Process. Technol. 85 (2004) 947-967.

[8] M. Iino, M.C. Matsuda, Carbon disulfide-pyridine mixture, a new efficient extraction solvent for coal, Fuel 63 (1983) 744-746.

[9] M. Iino, T. Takanohashi, S. Obara, H. Imeda, Y. Sanokawa, Characterization of the extracts and residues from $\mathrm{CS}_{2}-\mathrm{N}$-methylpyrrolidone mixed solvent extraction, Fuel 68 (1989) 1588-1593.

[10] K. Takahashi, K. Norinaga, Y. Masui, M. Iino, Effect of addition of salts on coal extraction with carbon disulfide/N-ethyl-2-pyrrolidinone solvent, Energy Fuels 15 (2001) 141-146.

[11] P.G. Stansberry, A.H. Stiller, J.W. Zondlo, C. Chen, B. Bland, D. Fenton, Research on Carbon Products from Coal Using an Extractive Process, West Virginia University, USA, 2002.

[12] H. Shui, Z. Wang, G. Wang, Effect of hydrothermal treatment on the extraction of coal in the $\mathrm{CS}_{2}$ /NMP mixed solvent, Fuel 85 (2006) 1798-1802.

[13] D.L. Morgan, Coal Solubilization, 1996 US Pat 5120430.

[14] D.L. Morgan, Alkali-induced coal solubilisation, Am. Chem. Soc. Div. Fuel Chem. (1992) 1996 Preprints, 15;

D.L. Morgan, A new solution-based coal upgrading process, ACS: Div. Fuel Chem. 4 (1992) 1996 Preprints. 
[15] J. Maire, J. Mering, in: P.L. Walker Jr. (Ed.), Chemistry and Physics of Carbon, vol. 6, Marcel Dekker, New York, 1970, p. 125.

[16] A. Marzec, Towards an understanding of the coal structure: a review, Fuel Process. Technol. 77-78 (2002) 25-32.

[17] C. Reichardt, Solvents and solvent effects: an introduction, Org. Process Res. Dev. 11 (2007) 105-113.

[18] A.R. Katritzky, D.C. Fara, H. Yang, K. Tämm, Quantitative measures of solvent polarity, Chem. Rev. 104 (2004) 175-198.

[19] E.M. Kosower, The effect of solvent on spectra. III. The use of Z-values in connection with kinetic data, J. Am. Chem. Soc. 80 (1958) 3267-3270.

[20] Y. Marcus, The properties of organic liquids that are relevant to their use as solvating solvents, Chem. Soc. Rev. 22 (1993) 409-416.

[21] C. Reichardt, Solvatochromic dyes as solvent polarity indicators, Chem. Rev. 94 (1994) 2319-2358.

[22] V. Gutmann, E. Wychera, Coordination reactions in non aqueous solutions - the role of the donor strength, Inorg. Nucl. Chem. Lett. 2 (1966) 257-260.

[23] U. Mayer, V. Gutmann, W. Gerger, The acceptor number - a quantitative empirical parameter for the electrophilic properties of solvents, Monatsh. Chem. 106 (1975) $1235-1257$.

[24] M.J. Kamlet, J.-L.M. Abboud, M.H. Abraham, R.W. Taft, Linear solvation energy relationships. 23. A comprehensive collection of the solvatochromic parameters, $\pi^{*}, \alpha$, and $\beta$, and some methods for simplifying the generalized solvatochromic equation, J. Org. Chem. 48 (1983) 2877-2887.
[25] C.G. Swain, M.S. Swain, A.L. Powell, S. Alunni, Solvent effects on chemical reactivity. Evaluation of anion and cation solvation components, J. Am. Chem. Soc. 105 (1983) 502-513.

[26] A. Marzec, M. Jozwa, K. Betlej, M. Sobkowiak, Bituminous coal extraction in terms of electron-donor and -acceptor interactions in the solvent/coal system, Fuel Process. Technol. 2 (1979) 35-44.

[27] J. Szeliga, A. Marzec, Swelling of coal in relation to solvent electron-donor numbers, Fuel 62 (1983) 1229-1231.

[28] A. Marzec, W. Kisielow, Mechanism of swelling and extraction and coal structure, Fuel 62 (1983) 977-979.

[29] M.B. Jones, J.K. Argasinski, Predictors of solvent effectiveness for dissolution of coal preasphaltenes, Fuel 64 (1985) 1547-1551.

[30] P.J. Hall, H. Marsha, K.M. Thomas, Solvent induced swelling of coals to study macromolecular structure, Fuel 67 (1988) 863-866.

[31] E.S.V. Giray, C. Chen, T. Takanohashi, M. Iino, Increase of the extraction yields of coals by the addition of aromatic amines, Fuel 79 (2000) 1533-1538.

[32] G.R. Dyrkacz, C.A.A. Bloomquist, Solvent extraction of separated macerals in carbon disulfide/N-methylpyrrolidone, Energy Fuels 15 (2001) 1409-1413.

[33] Y. Otake, E.M. Suuberg, Solvent swelling rates of low rank coals and implications regarding their structure, Fuel 77 (1998) 901-904. 